\title{
Adult and Continuing Education in Kenya: The Need for Transformative Leadership
}

\author{
Benard O. Nyatuka ${ }^{1, *} \&$ Judah M. Ndiku ${ }^{2}$ \\ ${ }^{1}$ Department of Educational Foundations, MasindeMuliro University of Science \& Technology, Kakamega, Kenya \\ ${ }^{2}$ Department of Educational Planning \& Management, MasindeMuliro University of Science \& Technology, \\ Kakamega, Kenya \\ *Corresponding author: Department of Educational Foundations, MasindeMuliro University of Science \& \\ Technology, P.O. Box 190-50100, Kakamega, Kenya. E-mail: bomenge@yahoo.com
}

Received: November 20, 2014

doi:10.5430/wje.v5n1p52
Accepted: December 17, 2014 Online Published: January 18, 2015

URL: http://dx.doi.org/10.5430/wje.v5n1p52

\begin{abstract}
As a multidisciplinary process, Adult and Continuing Education (ACE) is meant to foster efficient lifelong learning throughout life. To achieve this, it should be geared towards providing knowledge, skills as well as attitudes that ensure equal opportunities to life, meeting the needs of individuals of all ages so as to understand the world and the changes being experienced. In a bid to attain a newly industrialized status, Kenya's Vision 2030 development plan endeavours to develop the relevant human resource base through, among others, ACE. However, the provision of $\mathrm{ACE}$ in Kenya faces such challenges as inappropriate learning environment, inadequate instructional materials and the inability to balance career and family demands. This is partly due to inept leadership, non-adherence to the relevant policy guidelines and pieces of legislation. In this paper, it is asserted that in order to achieve the aims of ACE, embracing transformative leadership is paramount. Thus, this piece of work is informed by the theory of transformational leadership which lays emphasis on how leaders, in various fields, can actually impact and or transform their subjects positively, and vice versa. In addition to exploring the policy and legislative frameworks concerning the provision of ACE in Kenya, this paper provides some intervention measures to the outstanding challenges.
\end{abstract}

Keywords: adult and continuing education; challenges; legislative and policy frameworks; prospects and transformational leadership

\section{Introduction}

Kenya's national philosophy of education underscores the need to develop the human resource so as to attain the country's development goals (Republic of Kenya-ROK, 2012). Accordingly, education in Kenya should be geared towards developing one's potential fully. Among others, this will help produce individuals who are intellectually, physically and emotionally sound. In specific terms, such an education should make one to be patriotic, humane, honest and have mutual respect as well as high moral status degree.

Indeed, the current national policies and Constitution take cognizance of the fact that all citizens have a right to basic education (ROK, 2005a; 2010; 2012). This is in line with international education commitments as well as conventions, including the Jomtien Protocols and the Millennium Development Goals to which Kenya is a signatory (ROK, 2007b).It is important to note that ACE provides avenues for those who are not within the formal school set up to reap the fruits of education. Other than improving one's professional qualifications, ACE is aimed at achieving civic, social, moral and cultural attitudes as well as skills necessary in order to progress in every sphere of life. And, to achieve this, ACE programmes should be consciously designed to meet specific learning needs.

As per Ndiku, Muthamia, Ipara and Obaki (2009), lifelong learning is vital, especially in coping with the global trends in technology, politics and the economy. This, they assert, ensures citizens fit well in society and harness the environment sustainably. Since independence, Kenya has made effort to reduce adult illiteracy so as to enhance its socio- economic development (UNESCO, 2007). Indeed, the milestones towards achieving adult literacy were 
recognized soon after independence in 1963 when the aims of adult education were identified, including to: curb illiteracy, impart relevant knowledge, skills and attitude for survival, foster self-esteem and inculcate desirable behavior in as far as life and society are concerned. With these objectives in mind, the initial subject matter in the adult education programme included literacy, health and nutrition, family life, agriculture, environmental studies and civics (Ndiku et al, 2009; Kibera, 1997). This content is still relevant today.

It was hoped that this curriculum, if well implemented would lead to transformation of the lives of the many otherwise illiterate adults. In 1979, the Department of Adult Education was established in the Ministry of Culture and Social Services to, among others, spearhead a national literacy programme (UNESCO, 2007). This bold step saw the establishment of adult education centers in most parts of the country. In 2002, the coordination of adult education was moved to the Ministry of Education. A key outcome of housing adult education in the Ministry of Education was a gradual increase in enrolment in adult learners. For example, there were about 250,000 such learners in 2007 and 291,000 of them in 2012.

While the country reforms the different social institutions, it will be required to provide the requisite education, including ACE to the target groups. Among others, such a venture should embrace progressive management and leadership styles, attitude change as well as fostering a knowledgeable and cohesive society with a tradition of national ideals and basic human rights (ROK, 2012). Further, education and training should be geared towards enabling society to cherish science, technology and innovation, preserve and sustainably harness the environment for development. In other words, the education and training sector should enable society exploit opportunities and take responsibility.

Indeed, so as to attain the envisioned growth, whether economic, social or political, focus should be directed towards the enhancement of individuals by promoting and sustaining ACE, just like higher education, technical and vocational training. Ndiku et al (2009) observe that provision of ACE to citizens is mandatory if the country is to achieve the projections of the Kenya Vision 2030. Accordingly, the country is committed to achieving an adult literacy rate of $80 \%$ by 2030 .

However, the provision of ACE in Kenya faces a myriad of challenges, ranging from poor leadership and funding as well as attitude to low learning achievement levels among the affected learners. Guided by the theory of transformational leadership, this paper explores the legislative as well as policy frameworks guiding the provision of ACE in Kenya, the attendant challenges and intervention measures geared towards motivating the adult learners, boosting their confidence and self-esteem so as to enable them remain lifelong learners. The prospects of ACE provision in the country are also presented.

\section{Theoretical Framework}

This piece of work is guided by the transformational leadership theory as advanced by Bernard M. Bass (Kendra, 2014; Bass \& Riggio, 2008). Accordingly, transformational leadership can be defined on the effect that it has on the subjects. More specifically, transformational leaders are those who stimulate and inspire subjects to realize extraordinary outcomes thereby developing their own leadership capacities. Transformational leaders assist followers grow and develop into leaders. This is achieved by paying attention to individual followers' needs, including empowering them as well as matching the goals of individual followers, the leader, the group and the larger organization.

More recently, Bass has argued that authentic transformational leadership is anchored in three moral foundations which are based on four components (Changing Minds, 2013). The moral aspects are: the leader's moral character; the ethical values contained in the leader's vision, articulation and programme as well as the moral standing of the processes of social ethical choice and action that leaders as well as followers engage in and pursue collectively. On the other hand, the transformational leadership components include intellectual stimulation; individualized consideration; inspirational motivation and idealized influence (Bass \&Riggio, 2006).

In intellectual stimulation, transformational leaders challenge the status quo and lay emphasis on creativity among followers. In particular, the leader urges followers to find new ways of doing things and new opportunities to learn. Regarding individualized consideration, the transformational leader offers support and encouragement to the individual subjects. In an effort to promote supportive relationships, transformational leaders keep lines of communication open in a bid to make followers have the freedom to exchange ideas as well as allow leaders offer direct recognition of the unique contributions of each follower.

Inspirational motivation means that transformational leaders have clear vision that they are able to articulate to 
followers (Changing Minds, 2013). Accordingly, transformational leaders are also able to assist subjects feel the same passion and motivation to achieve certain goals. Concerning idealized influence, the transformational leader acts as a role model for subjects. And, because followers trust and respect the leader, they emulate and internalize his or her ideas.

The transformational leadership theory is relevant to this paper in two ways. First, it can be argued that much of what has been achieved in ACE in the country, particularly since independence borrows heavily from the theory. Second, it is asserted that much more stands to be realized if the ideals of the theory are embraced, especially in the country's present and future endeavours in as far as ACE provision is concerned.

\section{Legislative and Policy Frameworks Guiding Ace in Kenya}

Much of the success of Kenya's ACE sub-sector has been realized overtime due to the innovation and transformative ideas enshrined in policy formulation, review and legislation. As a demonstration of the commitment of the independent government towards promotion of ACE, the Board of Adult Education was established through an Act of Parliament in 1966 (ROK, 2007a; Ndiku, et al, 2009). The board was mandated to co-ordinate, advice and regulate ACE in Kenya. Further, the success of provision of ACE has been boosted by its recognition in several other policy documents on education. For instance, since 1997 to date different policy papers on education and development underscore the importance of ACE. They include: the Master Plan on Education and Training (MPET) 1997-2010 (ROK, 1998) as well as the report on Totally Integrated Quality Education and Training (TIQET) of 1999 (ROK, 1999), Poverty Reduction Strategy Paper (PRSP) 2001-2003, Economic Recovery Strategy for Wealth and Employment (ERSWEC) 2003-2007 and Sessional Paper No. 1 of 2005 on a Policy Framework for Education, Training and Research (ROK, 2005a).

Other important policy documents concerning ACE are the Kenya Education Sector Support Programme (KESSP) 2005-2010 (ROK, 2005b), National Youth Policy for Polytechnics (2007), Policy Paper on Adult and Continuing Education (2007) and the Gender Policy in Education (ROK, 2007c).The Constitution of Kenya stipulates that basic education is a basic human right (ROK, 2010). In line with the Constitution, the Basic Education Act (2013) was enacted to guide delivery of basic education, that is, ACE, pre-primary education, primary education, secondary education and special needs education. According to the Fifth Schedule of the Act, there shall be a special board of ACE whose functions include to: advise the Cabinet Secretary (CS) responsible for education on any matter concerning ACE; advise on the co-ordination and regulation of all the providers of ACE, including the involved institutions as well as identify and assess the need for new developments in ACE (ROK, 2013).

Other functions of the ACE board are to: stimulate and encourage activities in ACE; report annually to the CS on the progress and development of ACE as well as advise the National Education Board on matters regarding ACE. At the county level, the functions of the County Education Committee shall be to advise the County Education Board on the activities of ACE. And, as per ROK (2012), the objectives of ACE are to: curb illiteracy among the citizens; equip learners for global citizenship; sustain and foster multiple literacy; enhance acquisition of requisite knowledge, skills and attitudes among learners in a bid to promote adaptation to new technologies as well as production skills. Other objectives of ACE include to: promote self-esteem, values and desirable behaviour; increase access, participation and retention in ACE and lifelong learning as well as train local personnel for rural development through participatory, integrated development approach using multi-purpose training institutes.

\section{Challenges Facing Ace in Kenya}

As pointed out earlier on, a myriad of obstacles stand in the way of ACE programmes, thereby slowing down realization of the envisaged goals. Notably, some challenges concerning governance in the field of ACE include inefficiency in the management of resources, utilization and weak accountability. For instance, funds disbursed to the ACE institutions, especially those managed by the Ministry of Education are sometimes not directed towards the intended goals (ROK, 2012). Inefficient monitoring and tracking systems alongside a heavily centralized hierarchical and bureaucratic decision making system also leads to mismanagement. Such a situation calls for transformative leadership so as to achieve the envisaged goals.

It is worth noting that while the Constitution emphasizes on devolution in as far as management of education is concerned, policy making largely remains the responsibility of the national government (Sotz, 2011). Such a scenario could partially explain the challenges the delivery of ACE in the country is grappling with. Unreliable data is another challenge worth mentioning in as far as governance and management of ACE is concerned. Particularly, without 
legal provisions in place to guard against misinformation or non-cooperation with respect to relevant data, those in charge of departments as well as institutions release data that is not reliable to fit their unique circumstances or hide their shortcomings.

It is also worth to note that the provision of ACE throughout Kenya has previously suffered because of housing the department of ACE in various ministries since 1966, apart from being poorly funded. The Kenya National Adult Literacy Survey report (ROK, 2007a) established that $61.5 \%$ of the adult population, that is, those aged 15 years and above had only achieved the minimum level of literacy, meaning that $38.5 \%$ or a whopping 7.8 million others were illiterate. The survey also found out that a paltry $29.6 \%$ of the adult population had acquired the appropriate literacy competencies. It is important to observe that in order to achieve the Kenya Vision 2030, a change of attitude is required to create and sustain a responsible as well as intact society.

Although one of the goals of ACE is to improve Kenya's measurable learning outcomes in literacy, numeracy and communication skills (ROK, 2012), access to ACE programmes is low and both gender and regional disparities are glaring (Ndiku, et al, 2009). For example, while there were 147,940 (37,093 males and 110,487 females) learners in adult education centres in 1990, the number dropped to 93,903 (25,802 males and 68,101 females) in 2000. The number however, increased slightly in 2005 to 107,662 (29,205 males and 78,457 females). This translates to $21.1 \%$ and $72.9 \%$ for males and females, respectively. As per ROK (2007a), there are high regional disparities in literacy achievement, with the defunct Nairobi and North Eastern provinces recording a high of $87.1 \%$ and a low of $8 \%$, respectively.

According to Ndiku, et al (2009), poor enrolment in literacy classes involving adult learners in Kenya is due to the failure to hire sufficient and qualified teachers. This scenario is compounded by the fact that there is higher turnover of staff and volunteer teachers in ACE facilities. The study also revealed that a number of social factors discourage some adults from attending classes. Accordingly, adult learners either come late or miss school altogether due to participation in such social functions as circumcision, marriage and funerals. Related reasons that prevented learners from attending classes involved cases where the young and older learners as well as husbands and wives were mixed, while Muslims did not want to be taught by female instructors. Some learners, the study revealed, dropped out because of language barrier due to ethnicity or dialects and being taught by what they considered to be very young teachers. This requires communities to be sensitized so as to discard those cultural beliefs and practices which are retrogressive. Other learners remained absent or came to class late due to engagement in such economic activities as trade, planting and harvesting crops.

Inadequate capitation grants for instructional materials is another major challenge facing ACE (ROK, 2007a). Thus, there is need for the government to direct adequate funds to purchase appropriate as well as adequate instructional resources. Additionally, training programmes need to be expanded to enable the concerned teachers to manage adult learning centres both professionally and effectively. Ndiku, et al (2009) found out that adult learners dropped out due to the instructor's incompetence. Particularly, some adult education teachers were found to be quite fast in delivery of content. This way, they did not take into consideration individual differences among the learners. Other instructors were reported to be attending school irregularly. Further, the study revealed that a big fraction of the teachers were unable to improvise teaching as well as learning materials and/or resources whenever there was a shortage.

And, according to ROK (2012), adult education teachers are inadequately remunerated and are largely volunteers. They are usually either retired teachers or secondary school leavers without any form of professional training.Indeed, meeting the goals of ACE requires both structural and curriculum reform to boost literacy levels and align it to the ideals of the Constitution and the Kenya Vision 2030. Clearly, transformative leaders are required, more than ever before, to remedy this scenario.

Overall, the above as well as other challenges have led to low enthusiasm in as far as enrolment in adult education classes is concerned (Ndiku, et al; Seetharamu \& Devi, 2010). Among others, it is imperative to establish conducive adult learning centres which are equipped with appropriate pieces of furniture. To achieve this, communities, non governmental organizations, sponsors, development partners and relevant stakeholders need to supplement on this course. Given that learners' participation in ACE classes is basically voluntary, they can be motivated if their educators address their aspirations (Seetharamu\& Devi, 2010). This can go a long way in improving adult learner recruitment as well as achievement. According to Nafukho, Amutabi and Otunga(2005), efforts should be made to motivate adult learners and emphasize on the significance of lifelong learning. More importantly, providing focused leadership as well as management remains a crucial remedy to these challenges. 


\section{Prospects of Ace in Kenya}

As a component of basic education, ACE has been embraced in Kenya so as to boost its social, economic and political development endeavours. This is in appreciation of the fact that the quality of education that citizens receive highly dictates the level of development of any nation (ROK, 2012). Indeed, given that ACE has the potential to move the country forward in as far as its development agenda is concerned, it should be re-engineered to meet the ever growing demand of both the present as well as future.

As the country's development plan, the Kenya Vision 2030 recognizes the role of ACE in acquiring the knowledge, skills and attitudes required to implement the initiatives stipulated in its pillars. Particularly, the Medium-Term plan for the Kenya Vision 2030 sets to significantly increase adult literacy (ROK, 2007a). Accordingly, this involves expanding the provision of ACE across the 47 counties as well as making it to be in tandem with what the learners need.

Commendably, the government of Kenya has formulated the goals of ACE and should inform policies made at various levels. Such goals are aimed at: promoting patriotism among citizens and its varied cultures, fostering unity of the nation and assisting the citizens exercise their rights, roles and obligations (ROK, 2008). Particularly, citizens need to appreciate interdependency at the international stage. Additionally, the goals aim at providing knowledge, technical and vocational skills that make individuals to excel in whatever they do. In other words, the goals are aimed at enabling individuals to effectively participate in the development of the nation and in enhancing the quality of their own lives. Further, the goals are meant to help the citizens be engaged effectively as well as intelligently in the prudent management of their natural and other resources, that is, in the preservation of the environment for their own survival and that of the entire world. Also, the goals aim at inculcating desirable values and attitudes that are required for self-fulfillment, protection of the vulnerable and marginalized as well as for effective participation in democratic processes (ROK, 2008).

But there are numerous challenges that Kenya grapples with, particularly in its efforts to provide ACE. One such key challenge is inept leadership (ROK, 2005a; 2005b). Thus, strengthening governance, management and leadership capabilities among those involved in running the education sector, including the personnel charged with the provision of ACE at all levels is paramount. According to ROK (2012), governance is a process that involves provision of leadership regarding policy, oversight and strategic guidance on managing resources, service delivery as well as formulating and implementing appropriate policies and regulations.

Adherence to the various policy guidelines and legislation regarding ACE is at times wanting, a practice that needs to be curbed. As stipulated in ROK (2012), the government should commit itself to institutionalizing both strategic and transformative leadership in education as well as making human resource development key to the Ministry of Education's development.

Apparently, a good proportion of people who are educated, that is, armed with relevant knowledge, skills and attitudes are required so as to realize Kenya's social, economic and political goals as stipulated in Vision 2030 (ROK, 2007b). As per ROK (2012), successful nations as well as individual organizations invest heavily on the development of the capacity of the human resource. Indeed, this is one of the most crucial resources needed to achieve any form of development. Thus, to attain the goals of ACE, the Ministry of Education and the rest of the relevant stakeholders need to be meaningfully engaged in this venture.

More importantly, transformative leaders are required in order to achieve the goals of ACE in Kenya. It is imperative to note that virtually any move made towards improving the ACE sub-sector calls for capacity enhancement by way of informed and proactive leadership; well defined goals of management, targets and structures; development and implementation of a human resource development policy as well as a clear staff appraisal system. This way, Kenya stands to reform the ACE sub-sector immensely.

\section{References}

Bass, B. M., \& Riggio, R. E. (2006). Transformational Leadership Theory (2nd ed). London. Routledge.

Bass, B. M., \& Riggio, R. E. (2008). Transformational Leadership Theory. Mahwah, New Jersey: Lawrence Erlbaum Associates, Inc.

Changing Minds (2013). Bass' Transformational Leadership Theory. Retrieved from http://changingminds.org/disciplines/leadership/theories/bass_transformational.htm

Kendra, C (2014). What Is Transformational Leadership? How Transformational Leadership. Inspire. Retrieved 
from http://psychology.About.com/od/leadership/a/transformational.htm

Kibera, W.L. (1997). The State of the Art of Adult Education and Didactic Materials in Kenya: Agenda Perspective. Journal of Kenya Adult Education Association, 3(2). In: UNESCO/UNITWIN CHAIRS STRATEGIC Planning Workshop at the University of Nairobi-15-17 July, 1997. AIDS, 24(6), 891-7.

Nafukho, F.M., Amutabi, M., \& Otunga, R. (2005). Foundations of Adult Education in Africa. Cape Town. Pearson Education.

Ndiku, J.M., Muthamia, H., Ipara, O., \& Obaki, S. (2009). Adult Education Learners' Recruitment: Challenges and Prospects for Re-engineered Access to Education in Kenya. Educational Research and Review, 4(7), 345-353.

Republic of Kenya (ROK, 1998). Master Plan of Education and Training 1997-2010. Nairobi. Jomo Kenyatta Foundation.

Republic of Kenya (ROK, 1999). Totally Intergrated Quality Education and Training (TIQET). Report of the Commission of the Inquiry into the Education System of Kenya. Nairobi. Government Printer.

Republic of Kenya (ROK, 2005a). Sessional Paper No.1 on A Policy Framework for Education, Training and Research. Nairobi: Ministry of Education.

Republic of Kenya (ROK, 2005b). Kenya Education Sector Support Programme (KESSP) 2005- 2010: Delivering Quality Education and Training to all Kenyans. Nairobi. Ministry of Education.

Republic of Kenya (ROK, 2007a). The Kenya National Adult Literacy Survey Report (2007). Nairobi. Kenya National Bureau of Statistics.

Republic of Kenya (ROK, 2007b). Kenya Vision 2030.Nairobi. Ministry of Planning, National Development and Vision 2030.

Republic of Kenya (ROK, 2007c). Gender Policy in Education. Nairobi. Ministry of Education.

Republic of Kenya (ROK, 2008). The Development and State of Art of Adult Learning And Education (ALE) National Report of Kenya. Nairobi: Ministry of National Development and Planning.

Republic of Kenya (ROK, 2010). The Constitution of the Republic of Kenya. Nairobi: Government Printer.

Republic of Kenya (ROK, 2012). Sessional Paper No. 14 of 2012 on Reforming Education and Training Sectors in Kenya. Nairobi. Ministry of Education and Ministry of Higher Education, Science and Technology.

Republic of Kenya (ROK, 2013). The Basic Education Act. Nairobi. Government Printer.

Riggio, R.E (2009). Are You a Transformational Leader. Psychology Today. Retrieved from http://blogs.psychologytoday.com/blog/cutting-edge-leadership/200903/are-you-transformational-leader

Seetharamu, A. S., \& Devi, M.D. U. (2010). Adult Education. New Delhi. Ashishi Publishing House.

Sotz, C. (2011). What Does Kenya's New Constitution Say About Education? Nairobi: Strathmore University. Retrieved from http://www.strathmore.edu/News.Php?NewsID=521

UNESCO. (2007). Nairobi Education Sector-Kenya National Adult Literacy. Retrieved from http://www.education.nairobi-unesco.org/index.php 